\title{
Complement activation in thrombotic thrombocytopenic purpura
}

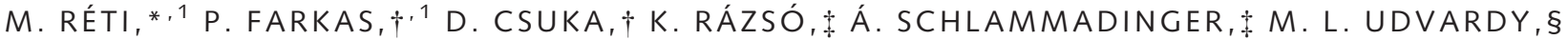

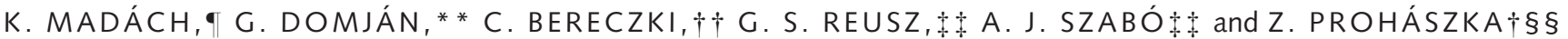 \\ *Department of Hematology and Stem Cell Transplantation, St István and St László Hospital of Budapest; †3rd Department of Medicine, \\ Semmelweis University, Budapest; $\$ 2$ nd Department of Medicine, University of Debrecen, Debrecen; §Clinical Research Center, University of \\ Debrecen, Debrecen; -Department of Anaesthesiology and Intensive Therapy, Semmelweis University, Budapest; **1st Department of Internal \\ Medicine, Semmelweis University; ††Department of Pediatrics, University of Szeged, Szeged; $+\$ 1$ st Department of Pediatrics, Semme/weis \\ University, Budapest; and §§Research Group of Inflammation Biology and Immunogenomics, HAS-SU, Budapest, Hungary
}

To cite this article: Réti M, Farkas P, Csuka D, Rázsó K, Schlammadinger Á, Udvardy ML, Madách K, Domján G, Bereczki C, Reusz GS, Szabó AJ, Prohászka Z. Complement activation in thrombotic thrombocytopenic purpura. J Thromb Haemost 2012; 10: 791-8.

Summary. Background: Ultra-large von Willebrand factor and deficiency of its cleaving protease are important factors in the events leading to thrombotic microangiopathy; however, the mechanisms involved are only partly understood. Whereas pathological activation of the alternative complement pathway is linked to atypical hemolytic uremic syndrome, the role of complement activation in thrombotic thrombocytopenic purpura (TTP) is unknown. The aim of this study was to investigate whether signs of complement activation are characteristic of TTP. Patients and methods: Twenty-three patients with TTP (18 women, median age 38 years) and 17 healthy controls (13 women, median age 38 years) were included. Complement parameters (C3, Factors H, I, B and total alternative pathway activity) together with complement activation fragments (C3a) or complexes (C1rs-INH, C3bBbP, sC5b9) were measured by ELISA or RID. ADAMTS13 activity and anti-ADAMTS13 inhibitory antibodies were measured by the VWF-FRET73 assay. Results: Increased levels of $\mathrm{C} 3 \mathrm{a}$, and $\mathrm{SC} 5 \mathrm{~b} 9$ were observed in TTP during acute episodes, as compared with healthy controls. Decreased complement C3 levels indicative of complement consumption occurred in $15 \%$ of acute TTP patients. Significant decrease of complement activation products $\mathrm{C} 3 \mathrm{a}$ and $\mathrm{SC} 5 \mathrm{~b} 9$ was observed during plasma exchange (PEX). The sustained presence of anti-ADAMTS13 inhibitory antibodies in complete remission was associated with increased complement activation. Conclusion: These data document in

Correspondence: Zoltán Prohászka, 3rd Department of Medicine, Semmelweis University, H-1125 Budapest, Kútvölgyi st. 4, Budapest 1125 , Hungary.

Tel.: +36 1 3251379; 3620 8250962; fax: +36 12129351 .

E-mail: prohoz@kut.sote.hu

${ }^{1}$ These two authors contributed equally to this work.

Received 8 July 2011, accepted 13 February 2012 an observational study the presence of complement activation in TTP. Further investigation is needed to determine its potential pathogenetic significance.

Keywords: ADAMTS13 inhibitor, complement activation, TTP.

\section{Introduction}

Thrombotic thrombocytopenic purpura (TTP) is a life-threatening disease characterized by microvascular platelet-rich thrombi leading to multiple organ failure [1]. The main clinical features are consumptive thrombocytopenia, microangiopathic hemolytic anemia, neurological dysfunction, renal failure and fever. The plasma of patients contains ultra-large von Willebrand factor (ULVWF) multimers at disease onset, which are highly reactive with platelets. ULVWF multimers are secreted into the plasma by endothelial cells and platelets and rapidly processed into smaller and less reactive multimers by cleavage of VWF-cleaving protease [2]. VWF-cleaving protease is the 13th member of the ADAMTS (a-disintegrin and metalloproteinase with thrombospondin type 1 motifs) family, ADAMTS13. Two mechanisms for deficiency of ADAMTS13 activity have been identified: in the majority of TTP patients inhibitory autoantibodies against ADAMTS13 are present [3], whereas in about $10 \%$ of the patients mutations of the ADAMTS13 gene cause congenital deficiency of the protease and result in a familial, autosomal recessive form of TTP [4].

The functional deficiency of ADAMTS13 plays a substantial role in the development of TTP, but its deficiency is not sufficient alone to cause TTP. Environmental factors and genetic modifiers may contribute to the full-blown manifestation of the disease. As suggested earlier, genes encoding proteins involved in the regulation of the coagulation cascade, VWF, or platelet function, components of the endothelial vessel surface or the complement system may be implicated in 
susceptibility to develop thrombotic microangiopathy [5]. Previous findings suggest that abnormalities of complement activation may contribute to the development of thrombotic microangiopathy in patients with ADAMTS13 deficiency. Platelet-associated C3 was reported in patients with TTP [6], and low levels of $\mathrm{C} 3$ (indicative of complement activation and consumption) were also observed in four out of six patients with acute ADAMTS13-deficient TTP [7]. Ruiz-Torres [7] documented for the first time that complement initiated neutrophil activation and endothelial injury may have a crucial role in microvascular thrombosis in TTP patients with congenital or acquired ADAMTS13 deficiency. In this study, serum from patients with thrombotic microangiopathy was shown to cause $\mathrm{C} 3$ and membrane attack complex deposition and surface expression of P-selectin on the human microvascular endothelial cell line. The same sera also stimulated neutrophils to release reactive oxygen species and proteinases, leading to endothelial cell damage. All of these effects were abrogated by complement inactivation, confirming the important role of complement activation in TTP.

In line with these observations, some precipitating clinical factors, such as infections and pregnancy, are potential triggers of complement activation; however, most TTP patients present without triggers. On the other hand, epidemiologic evidence of an association between complement activation and TTP is missing. In addition, the activating pathway(s) of, and clinical factors associated with, complement activation in TTP are unknown. Furthermore, no information on the effect of plasma exchange on complement activation product levels in patients with TTP is available so far.

Therefore, we hypothesized that complement activation may associate with acute, ADAMTS13-deficient TTP and potentially contribute to the development of thrombotic microangiopathy. Accordingly, the aim of the current study was to formally investigate in a case-control design the association of complement activation with acute TTP, to examine the activation pathway(s) involved, and to assess whether complement activation products change during plasma exchange therapy.

\section{Materials and methods}

\section{Patients and definitions}

Twenty-three patients with TTP were enrolled in this singleresearch laboratory-based investigation providing diagnostic services (ADAMTS13 and complement measurements) since August 2007 for patients suspected of having HUS or TTP in Hungary. The patient enrollment was closed in January 2011. The following criteria were used to guide patient and sample selection.

Diagnosis of TTP was based on one or more episodes of Coombs-negative microangiopathic hemolytic anemia with thrombocytopenia defined as serum lactate dehydrogenase $(\mathrm{LDH})>450 \mathrm{U} \mathrm{L}^{-1}$, fragmented erythrocytes in the peripheral blood smear and platelet count $<150 \mathrm{G} \mathrm{L}^{-1}$; only patients with severely decreased ADAMTS13 activity levels $(<5 \%)$ were included in this study. Patients with acute oligoanuric renal failure were excluded from the study. Hematological remission (HR) was determined when platelet counts were $>150 \mathrm{G} \mathrm{L}^{-1}$ on two consecutive days without any sign of hemolysis even if there were any neurological, renal or other residual clinical symptoms, whereas complete remission (CR) was established when platelet count remained above the lower limit continuously for at least 1 month. Relapse was considered if disease activity reappeared after 1 month of platelet count continuously higher than $150 \mathrm{G} \mathrm{L}^{-1}$, and exacerbation was considered if TTP reactivated within 1 month.

Blood samples taken during an acute TTP episode (before the initiation of plasma exchange [PEX]-series, during PEXseries (taken before the next plasma exchange), within 2 weeks after stopping of PEX-series and also in CR) were available for 13 patients. The replacement fluids were $5 \%$ human albumin (30-50\% of total volume of substitution fluid) followed by fresh frozen plasma (50-70\% of total volume of substitution) to reduce the number of donor expositions. In another 10 TTP patients, samples taken only in complete remission were available, at the time-point of our investigations 4/10 had normal ADAMTS13 activity, but all of them had history of ADAMTS13 deficiency with inhibitors.

Healthy controls $(n=17)$ were selected according to age and gender from a consecutive series of healthy subjects recruited in an outpatient department providing regular health check-ups for healthy employees on a mandatory basis. Twenty-three per cent of the control women had history of pregnancy.

Blood samples (EDTA-anticoagulated plasma, sodium-citrate anticoagulated plasma and native serum) were taken by antecubital venipuncture or from a central catheter, and cells and supernatant separated by centrifugation and shipped in cooled packages $\left(-20^{\circ} \mathrm{C}\right)$ to the research laboratory, where aliquots were made and stored in ultrafreezers at $<-70{ }^{\circ} \mathrm{C}$ until determinations.

\section{Determination of the complement proteins and complement activation products}

Complement C3 (Roche Cobas Integra 800 (Tina-quant ${ }^{\circledR} \mathrm{C} 3 \mathrm{c}$ 2. ver. Cat. No.: 3001938, reference range 0.9-1.8 $\mathrm{g} \mathrm{L}^{-1}$ ), factor I and factor B (radial immunodiffusion, reference range for both, 70-130\%) and factor $\mathrm{H}$ (sandwich-enzyme-linked immunosorbent assay (ELISA), 127-447 $\mathrm{mg} \mathrm{L}^{-1}$ ) levels and total alternative pathway activity (Wieslab Comp AP330 kit, 70$105 \%$, Euro Diagnostica, Malmö, Sweden) were measured in serum samples. Levels of fragments C3a (MicroVue C3a des$\arg$ EIA A031, mean of healthy controls $129.6 \mathrm{ng} \mathrm{mL}^{-1}$ ), C4d (MicroVue C4d EIA, A008, mean $+2 \mathrm{SD}$ range 0.7$6.3 \mu \mathrm{g} \mathrm{mL}^{-1}$ ) and SC5b-9 (MicroVue SC5b-9 Plus EIA, A020, mean of healthy controls $200 \mathrm{ng} \mathrm{mL}^{-1}$, SD 85) were determined with commercial kits (Quidel, San Diego, CA, USA) according to the manufacturer's instructions in EDTA plasma samples. Within- and between-run coefficients of 
variations of the assays, as tested in our laboratory, were $<5.5 \%$ or $<13.5 \%$, respectively.

\section{Measurement of the complement activation product C3bBbP}

The concentration of $\mathrm{C} 3 \mathrm{bBbP}$ was determined with ELISA based on Cat et al. [8], with some modifications [9]. In brief: plates (Nunc, Maxisorp F96, Nunc GmbH, Langenselbold, Germany) were coated with 1:1000 diluted goat anti-human properdin (Incstar Corporation, Incstar, Stillwater, MN, USA) and after blocking 1:10 diluted EDTA-plasma samples and standards (normal human serum activated with zymosan, 1:100-1:12 800 diluted) were applied and developed by biotin-conjugated rabbit anti-human C3c (Dako, Dako Glostrup, Denmark) and streptavidin-peroxidase conjugate (Jackson Immunoresearch, UK; Jackson West Grove, PA, USA). Concentrations are expressed in units per $\mathrm{mL}$ sample: 1000 units correspond to the C3bBbP-content of $1 \mathrm{~mL} \mathrm{1:10}$ diluted, zymosan-treated normal human serum (considered as full activation of alternative pathway). Typical values of healthy adults are mean $3.4 \mathrm{U} \mathrm{mL}^{-1}$ and SD 1.03, and within- and between-run $\mathrm{CV} \%<5 \%$ and $<15 \%$, respectively [9].

\section{Measurement of C1rC1sC1-inh complex}

The serum concentration of $\mathrm{ClrClsC1}$-inh was determined by ELISA [8] as described, with some modifications [9]. In brief: plates (Nunc, Maxisorp F96) were coated with 1:500 diluted rabbit anti-human C1-inh (Dako), after blocking 1:200 diluted EDTA-plasma samples and standards (normal human serum activated with heat-aggregated $\operatorname{IgG}, 1: 500-1: 32000$ diluted) were added, followed by 1:500 diluted goat anti-human C1s (DiaSorin, DiaSorin Saluggia, Italy) developed by 1:1000 diluted peroxidase-conjugated rabbit anti-goat IgG (Jackson Immunoresearch). Concentrations are expressed in units per $\mathrm{mL}$ of sample; 1000 units correspond to the $\mathrm{ClrClsC1}$-inhcontent of $1 \mathrm{~mL}$ 1:500 diluted normal serum, treated with heataggregated $\operatorname{IgG}$ (considered as full activation of classical pathway). Typical healthy control values are mean $5.72 \mathrm{U} \mathrm{mL}^{-1}$ and $\mathrm{SD}$ 6.8; within- and between-run $\mathrm{CV} \%<15 \%[9]$.

\section{Determination of ADAMTS13 activity}

The fluorigenic substrate, FRETS-VWF73, was applied for the determination of ADAMTS13 enzyme activity as described [10]. Briefly, citrated plasma was diluted 1:20 in assay buffer (5 mm Bis-Tris, $25 \mathrm{~mm} \mathrm{CaCl} 2,0.005 \%$ Tween 20, pH 6.0) and mixed with $5 \mu \mathrm{M}$ FRETS-VWF73 substrate solution $(20 \mu \mathrm{L}$ each), in white 384-well plates. Fluorescence was measured at $37^{\circ} \mathrm{C}$ every $2 \mathrm{~min}$ for $1 \mathrm{~h}$ in a Chameleon microplate reader (Hidex, Turku, Finland) equipped with a $340 \mathrm{~nm}$ excitation and a $460 \mathrm{~nm}$ emission filter. The reaction rate was calculated by linear regression analysis of fluorescence over time. A 2-fold dilution series of normal human plasma (mixed from citrated plasma samples of 10 healthy blood donors) was applied as standard curve, and $100 \%$ ADAMTS13 activity was set at the reaction rate observed in the 1:20 diluted sample. The intraassay variation coefficient was $<5 \%$, and the inter-assay CV\% was 6-9\% (measured at $60 \%$ and $100 \%$ activity levels). The presence of anti-ADAMTS13 inhibitors was determined by mixing one part of the patient's sample with one part of normal pooled plasma, incubation at $37{ }^{\circ} \mathrm{C}$ for $2 \mathrm{~h}$, and measurement of ADAMTS13 activity of the sample. The presence of ADAMTS13 inhibitors was considered if the patient's original sample had $<7 \%$ activity, and that of the mixed sample was $<50 \%$.

\section{Statistical analysis}

The continuous variables reported in this study showed skewed distribution and according to the results of the Shapiro-Willk's test deviated from the normal distribution. Therefore, for descriptive purposes the values of each measurement are given as median and 25th-75th percentile or as numbers (per cent) and non-parametric tests were used for group comparisons; continuous variables between two groups were compared with the Mann-Whitney $U$-test, for three or more groups with the Kruskal-Wallis ANOvA by ranks test, and for repeated measures with the Friedman test. Dunn's post-test was used for group comparisons after analysis of variance. Pearson's correlation coefficients were calculated on log-transformed variables. Statistical analyses were carried out using STATISTICA 7.0 (StatSoft Inc., Tulsa, OK, USA), SPSS 13.01 (Apache Software Foundation, Chicago, DW, USA) and GraphPad Prism 4.03 (GraphPad Softwares Inc., La Jolla, CA, USA) softwares. Two tailed $P$ values were calculated and the significance level was put at a value of $P<0.050$.

\section{Results}

\section{Description of the patient cohort}

Clinical characteristics of the patients and controls are presented in Tables 1 and 2. Median age of the TTP patients was 38 years (IQ range 31-44), whereas in the healthy control group it was $38(31-46)$ years. The ratio of women to men (18/5 in patients and 13/4 in controls) was similar in patients and controls, and the BMI values of the study groups were similar $(P>0.05)$. On average, the first TTP episode presented in our patients at the age of 36 years, and there was a mean total number of episodes of 2.0 patient present. As for treatment regiment, taking all of the 47 episodes of the 23 patients into account, the following medications were applied: corticosteroids $100 \%$, cyclophosphamide $52 \%$, acetylsalicylic acid $43 \%$, rituximab $22 \%$, vincristine $30 \%$, azathioprine $22 \%$, intravenous immunoglobulin 9\%, Asasantin (dipyridamole + acetylsalicylic acid) or Persantin (dipyridamole) 13\%, LMWH $4 \%$, and two patients received ticlopidine in 1996. Splenectomy was carried out in three $(13 \%)$ patients. Neurological signs 
Table 1 Clinical data of the 23 patients with thrombotic thrombocytopenic purpura

\begin{tabular}{|c|c|c|c|c|c|c|c|c|c|}
\hline $\begin{array}{l}\text { Registry } \\
\text { code }\end{array}$ & Gender & $\begin{array}{l}\text { Age at } \\
\text { first } \\
\text { episode }\end{array}$ & $\begin{array}{l}\text { First TTP } \\
\text { episode }\end{array}$ & $\begin{array}{l}\text { Last TTP } \\
\text { episode }\end{array}$ & $\begin{array}{l}\text { Total no. } \\
\text { of TTP } \\
\text { episodes }\end{array}$ & $\begin{array}{l}\text { Severe } \\
\text { ADAMTS13 } \\
\text { deficiency } \\
\text { with inhibitor }\end{array}$ & $\begin{array}{l}\text { Therapy } \\
\text { (cumulative, } \\
\text { all episodes) }\end{array}$ & $\begin{array}{l}\text { Clinical } \\
\text { symptoms } \\
\text { (current/last } \\
\text { episode) }\end{array}$ & $\begin{array}{l}\text { No. of PEX } \\
\text { sessions } \\
\text { (current } \\
\text { episode) }\end{array}$ \\
\hline \multicolumn{10}{|c|}{ Acute TTP patients } \\
\hline HUN1 & $\mathrm{W}$ & 26 & 2007 & 2010 & 3 & Yes & S, IVIG, Rit & $\mathrm{N}$ & 15 \\
\hline HUN15 & M & 55 & 2008 & 2008 & 1 & Yes & $\mathrm{S}, \mathrm{Cy}$ & Abd & 10 \\
\hline HUN23 & M & 38 & 2008 & 2008 & 1 & Yes & $\mathrm{S}$ & $\mathrm{R}, \mathrm{Abd}$ & 12 \\
\hline HUN56 & $\mathrm{W}$ & 40 & 2006 & 2010 & 2 & Yes & $\begin{array}{l}\text { S, Cy, Asasantin, } \\
\text { LMWH }\end{array}$ & $\mathrm{N}$ & 8 \\
\hline HUN62 & $\mathrm{W}$ & 17 & 1991 & 2009 & 4 & Yes & $\begin{array}{l}\text { S, Cy, Persantin, } \\
\text { ASA }\end{array}$ & $\mathrm{N}$, Abd & 15 \\
\hline HUN68 & M & 43 & 2010 & 2010 & 1 & Yes & $\mathrm{S}, \mathrm{Cy}$ & $\mathrm{N}$ & 19 \\
\hline HUN72 & W & 13 & 2010 & 2010 & 1 & Yes & S, Cy, Rit & $\mathrm{N}, \mathrm{abd}$ & 15 \\
\hline HUN76 & W & 58 & 2010 & 2010 & 1 & Yes & $\mathrm{S}, \mathrm{Cy}, \mathrm{ASA}$ & $\mathrm{N}$ & 7 \\
\hline HUN85 & $\mathrm{W}$ & 49 & 2010 & 2010 & 1 & Yes & $\begin{array}{l}\text { S, Cy, IVIG, ASA, } \\
\text { VCR, Rit }\end{array}$ & $\mathrm{N}$ & 38 \\
\hline HUN86 & $\mathrm{W}$ & 42 & 2010 & 2010 & 1 & Yes & $\mathrm{S}, \mathrm{Cy}, \mathrm{ASA}$ & $\mathrm{N}$, Abd & 9 \\
\hline HUN126 & M & 36 & 2010 & 2011 & 2 & Yes & S, Cy, Rit & None & 28 \\
\hline HUN127 & $\mathrm{W}$ & 30 & 2010 & 2010 & 1 & Yes & S, Rit & $\mathrm{N}$ & 9 \\
\hline HUN131 & $\mathrm{W}$ & 39 & 2006 & 2011 & 2 & Yes & S, ASA & None & 4 \\
\hline \multicolumn{10}{|c|}{ TTP patients in complete remission } \\
\hline HUN3 & $\mathrm{M}$ & 29 & 1999 & 2006 & 3 & Yes & $S$, PEX & $\mathrm{N}$ & NA \\
\hline HUN28 & $\mathrm{W}$ & 35 & 2008 & 2008 & 1 & Yes & S, AZA, PEX & $\mathrm{N}, \mathrm{R}, \mathrm{Abd}$ & NA \\
\hline HUN31 & $\mathrm{W}$ & 31 & 2008 & 2008 & 1 & Yes & $\mathrm{S}, \mathrm{PEX}$ & None & NA \\
\hline HUN53 & W & 35 & 1994 & 1998 & 2 & Yes & $\begin{array}{l}\text { S, AZA, ASA, } \\
\text { Asasantin, PEX }\end{array}$ & $\mathrm{N}$ & NA \\
\hline HUN58 & $\mathrm{W}$ & 20 & 1983 & 2010 & 3 & Yes & $\begin{array}{l}\text { S, Cy, AZA, VCR, } \\
\text { PEX, ASA, Spl }\end{array}$ & $\mathrm{N}$ & NA \\
\hline HUN65 & $\mathrm{W}$ & 21 & 1995 & 2002 & 6 & Yes & $\begin{array}{l}\text { S, AZA, VCR, } \\
\text { ticlopidin (in 1995), } \\
\text { Spl, PEX }\end{array}$ & $\mathrm{N}, \mathrm{R}, \mathrm{Abd}$ & NA \\
\hline HUN70 & $\mathrm{W}$ & 44 & 2006 & 2006 & 1 & Yes & S, Cy, VCR, PEX & $\mathrm{N}$ & NA \\
\hline HUN78 & W & 38 & 2001 & 2001 & 1 & Yes & S, VCR, ASA, PEX & $\mathrm{N}, \mathrm{R}, \mathrm{Abd}$ & NA \\
\hline HUN89 & M & 19 & 1996 & 2003 & 4 & Yes & $\begin{array}{l}\text { S,VCR, ticlopidin (in } \\
\text { 1996), ASA, PEX }\end{array}$ & $\mathrm{N}$ & NA \\
\hline HUN115 & $\mathrm{W}$ & 41 & 2000 & 2006 & 4 & Yes & $\begin{array}{l}\text { S,Cy, VCR, AZA, } \\
\text { ASA, Spl, PEX }\end{array}$ & $\mathrm{N}$, Abd & NA \\
\hline
\end{tabular}

$\overline{\text { Abd, abdominal complaints; ASA, low-dose acetylsalicilic acid; AZA, azathioprine; Cy, cyclophosphamide; N, neurological signs; PEX, plasma }}$ exchange; R, renal function deterioration; S, corticosteroid; Spl, splenectomy; VCR, vincristine.

(78\%), abdominal complaints $(39 \%)$ and renal function deterioration (17\%) accompanying the last (current) TTP episode, were present in the patients, whereas $13 \%$ had hematological symptoms only. All of the patients were screened for autoantibodies against complement factor $\mathrm{H}$, and none of them was found to be positive. None of the patients has been diagnosed according to the ARA criteria as having SLE, antiphospholipid syndrome or any other systemic autoimmune disorder, based on testing of antinuclear-, anti-dsDNA, anticardiolipin autoantibodies, lupus anticoagulant and typical clinical signs. Documented triggering factors antecedent to acute TTP episodes were infrequent in this TTP cohort; only $2 /$ 23 pregnancies, 1/23 missed abortion and sepsis and 3/23 infections were documented. For patients seen with acute TTP episode a total of 15 (mean, 4-38, range) PEX sessions were required to reach remission. All of the 10 patients seen only during remission were previously successfully treated with therapeutic plasma exchange during acute TTP episodes.

\section{Complement activation in TTP}

As presented in Table 2, complement protein C3, factor I and alternative pathway activity levels were the same in the groups, whereas factor $\mathrm{B}$ and factor $\mathrm{H}$ concentrations were higher in TTP patients, significantly in complete remission as compared with healthy controls $(P<0.05)$. A decreased complement $\mathrm{C} 3$ level $\left(<0.9 \mathrm{~g} \mathrm{~L}^{-1}\right)$, indicative of severe complement activation and consumption, did occur in $2 / 13$ acute patients $(15 \%)$.

Complement activation products, characteristic of the classical/lectin pathway (C1rs-INH, C4d), alternative pathway (C3bBbP), terminal pathway (SC5b-9) and all pathways (C3a) were also measured in the patients. As presented in Table 2, higher C3a and SC5b-9 levels were observed in TTP patients, as compared with healthy controls, and this difference was statistically significant in patients with an acute TTP episode, before the initiation of PEX (both $P<0.01$ ). C1rs-INH complex, alternative pathway activation product $(\mathrm{C} 3 \mathrm{bBbP})$ and $\mathrm{C} 4 \mathrm{~d}$ levels were similar in the groups investigated. 
Table 2 Complement protein and activation product levels of the study groups

\begin{tabular}{|c|c|c|c|c|}
\hline Parameter & $\begin{array}{l}\text { Acute TTP, before } \\
\text { PEX-series, } n=13\end{array}$ & $\begin{array}{l}\text { TTP, complete } \\
\text { remission, } n=10\end{array}$ & $\begin{array}{l}\text { Healthy control, } \\
n=17\end{array}$ & $\begin{array}{l}\text { Kruskal-Wallis or } \\
\chi^{2} \text { test, } P\end{array}$ \\
\hline Age at blood draw (years) & $42(32-46)$ & $37(29-45)$ & $38(31-46)$ & 0.543 \\
\hline Gender $(\mathrm{f} / \mathrm{m})$ & $9 / 4$ & $9 / 1$ & $13 / 4$ & 0.346 \\
\hline BMI & $25.7(23.2-30.0)$ & $27.2(22.4-35.1)$ & $24.5(20.7-28.1)$ & 0.271 \\
\hline Complement $\mathrm{C} 3\left(\mathrm{~g} \mathrm{~L}^{-1}\right)$ & $1.49(1.14-1.90)$ & $1.56(1.46-2.12)$ & $1.2(1.06-1.45)$ & 0.158 \\
\hline Alternative pathway activity (\%) & $96(83-101)$ & $94(81-104)$ & $83(75-98)$ & 0.551 \\
\hline Factor B $(\%)$ & $114(92-138)$ & $127(111-155)^{*}$ & $92(77-111)$ & 0.013 \\
\hline Factor I (\%) & $126(101-146)$ & $114(106-130)$ & $107(81-122)$ & 0.087 \\
\hline Factor $\mathrm{H}\left(\mathrm{mg} \mathrm{L}^{-1}\right)$ & $385(283-538)$ & $622(401-697)^{*}$ & $301(211-397)$ & 0.032 \\
\hline $\mathrm{C} 1 \mathrm{r}-\mathrm{C} 1 \mathrm{~s}-\mathrm{C} 1 \mathrm{INH}\left(\mathrm{U} \mathrm{mL}^{-1}\right)$ & $8.81(5.11-13.33)$ & $4.51(3.11-9.97)$ & $7.18(4.01-9.61)$ & 0.224 \\
\hline $\mathrm{C} 4 \mathrm{~d}\left(\mathrm{mg} \mathrm{L}^{-1}\right)$ & $1.39(3.16-4.48)$ & $2.67(1.78-3.57)$ & $2.15(1.46-3.80)$ & 0.748 \\
\hline $\mathrm{C} 3 \mathrm{bBbP}\left(\mathrm{U} \mathrm{mL}^{-1}\right)$ & $1.99(1.34-6.80)$ & $2.21(1.59-3.31)$ & $1.71(1.32-2.99)$ & 0.496 \\
\hline Anaphylatoxin $\mathrm{C} 3 \mathrm{a}\left(\mathrm{ng} \mathrm{mL}^{-1}\right)$ & $195(170-514)^{* * *}$ & $133(117-221)$ & $103(80-138)$ & 0.001 \\
\hline SC5b-9 $\left(\mathrm{ng} \mathrm{mL}^{-1}\right)$ & $301(242-424)^{* *}$ & $241(216-330)$ & $181(141-283)$ & 0.006 \\
\hline
\end{tabular}

$* \mathrm{p}<0.05 ; * \mathrm{*} p<0.01 ; * * \mathrm{p}<0.001$
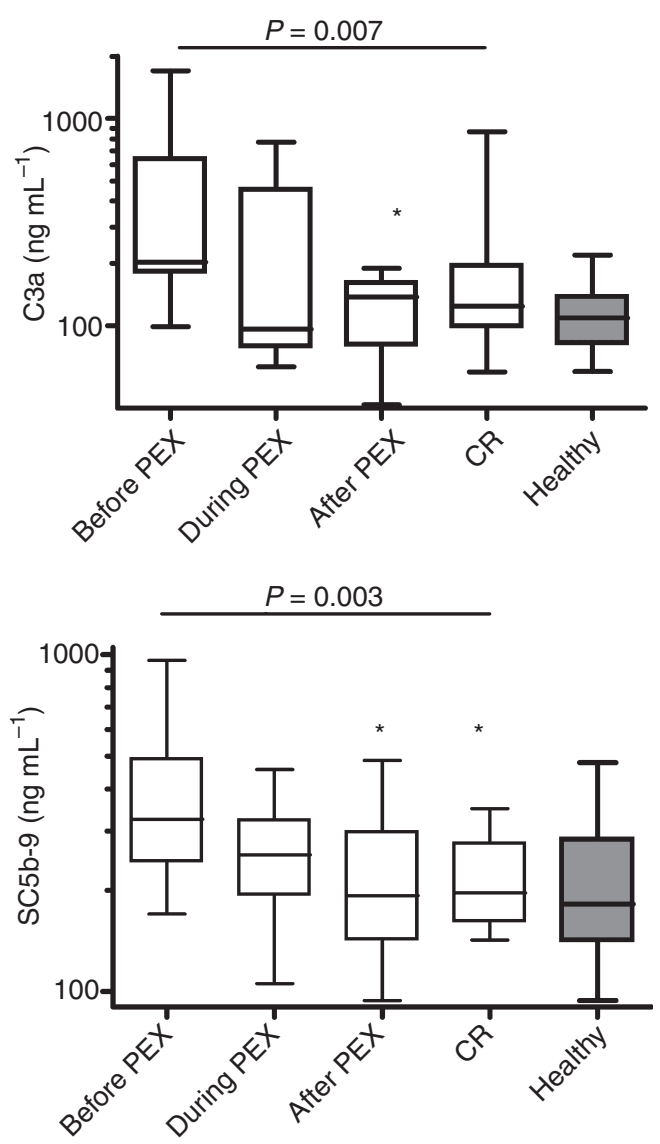

Fig. 1. Changes of complement activation product levels in TTP patients during a series of therapeutic plasma exchange. Results (median, IQ-range and minimum-maximum values) of TTP patients with available pre-PEX and follow-up samples $(n=13)$ are displayed. $P$-values of Friedman tests are indicated, * indicates if $P<0.05$ of Dunn's post-test, as compared with before PEX'.

The course of complement activation during PEX in TTP patients

In Fig. 1, data are presented for the 13 acute TTP patients for whom blood samples were available before, during and after the PEX-series. According to the results of paired, non-parametric analysis of variance, the complement activation product $\mathrm{C} 3 \mathrm{a}$ and SC5b-9 levels significantly declined during the PEX-series (all $P<0.05$ ). There was an immediate decrease of C3a and SC5b-9 concentrations in samples taken during a series of PEX sessions and/or right after stopping PEX (all $P<0.05$, Dunn's post-test), and complement activation products remained low during $\mathrm{CR}$. If $\mathrm{C} 3 \mathrm{a}$ and $\mathrm{SC} 5 \mathrm{~b}-9$ levels were analyzed in TTP patients and healthy controls together by means of Kruskall-Wallis ANOVA the differences were significant $(P=0.002$ for C3a and $P=0.033$ for SC5b-9), and the results of Dunn's post-test showed that C3a $(P<0.01)$ and SC5b-9 $(P<0.05)$ levels were significantly higher in the 'before PEX' group as compared with healthy controls. The decrease of these complement activation markers during and right after PEX was characteristic for all 13 patients, and was accompanied by an increase in platelet counts and achieving hematological and complete remission (data not shown).

\section{ADAMTS13 inhibitor as an initiating factor of complement activation in TTP}

ADAMTS13 inhibitor was present in all of our patients with acute TTP before the initiation of the PEX-series, and ADAMTS13 inhibitor turned out to be negative in eight of these 13 patients after achieving complete remission. We analyzed whether the disappearance of ADAMTS13 inhibitor was associated with decline of complement activation product levels during the PEX-series. As shown in Fig. 2, a clear decline was observed for $\mathrm{C} 4 \mathrm{~d}, \mathrm{C} 3 \mathrm{bBbP}$ and $\mathrm{C} 3 \mathrm{a}$ fragments in the ADAMTS13 inhibitor-negative group, while in the inhibitorpositive group these activation product levels did not decrease or increase.

\section{Initiating pathways of complement activation in TTP}

The characteristic feature of complement activation in acute TTP was the presence of activated C3 (C3a) and terminal 


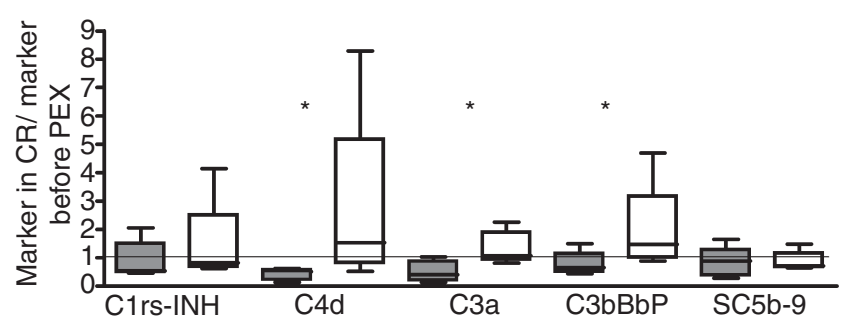

Fig. 2. Changes (CR/acute) of complement activation product levels measured before and after PEX-series, according to the ADAMTS13 inhibitor status in remission. All patients with acute TTP $(n=13)$ were ADAMTS13 inhibitor positive before the initiation of PEX-series, those who remained inhibitor positive after reaching complete remission are marked as clear $(n=5)$, whereas those who became ADAMTS13 inhibitor negative are marked as grey $(n=8)$. $P$-values $<0.05$ obtained in Mann-Whitney tests are marked with asterisks, comparing inhibitor negatives and positives.

complement complex (SC5b-9). Therefore we searched for associated clinical factors and biochemical markers by means of correlation analysis. The analysis was limited to the 13 patients with acute TTP and with available samples before the PEX-series. As shown in Table 3, a strong positive correlation was observed between activation markers $\mathrm{C} 4 \mathrm{~d}$ (classical and lectin pathways), $\mathrm{C} 3 \mathrm{bBbP}$ (alternative pathway) and $\mathrm{C} 3 \mathrm{a}$ or SC5b-9, respectively. Furthermore, C4d and C3bBbP levels also correlated with each other $(r=0.657, P=0.015)$. The levels of the classical pathway marker $\mathrm{C}$ 1rs-INH showed a weak, borderline correlation with C3a $(r=0.531, P=0.061)$ and $\mathrm{C} 4 \mathrm{~d}(r=0.528, P=0.064)$.

\section{Discussion}

Here we report that increased plasma levels of complement activation products were associated with acute TTP, showed a clear decrease when plasma exchange therapy was initiated, and were accompanied by an increase in platelet numbers and achieving clinical remission. Pathological over-activation with consumption of complement factors was observed in $15 \%$ of our acute ADAMTS13-deficient TTP patients, and clear-cut activation of the classical/lectin and alternative pathways with initiation of the terminal pathway was obviously shown. The sustained presence of ADAMTS13 inhibitor after acute TTP was associated with constantly high levels of complement activation product levels, including $\mathrm{C} 4 \mathrm{~d}, \mathrm{C} 3 \mathrm{a}$ and $\mathrm{C} 3 \mathrm{bBbP}$, even after achieving clinical remission, while disappearance of ADAMTS13 inhibitor was linked to decline of C4d and C3a levels in complete remission, indicative of the low level activation of classical/lectin pathways. Our results indicate that the complex therapy of an acute TTP episode (PEX series and immunosuppressive treatment) results in the disappearance of ADAMTS13 inhibitors and also in the decrease of complement activation.

Earlier Ruiz-Torres et al. [7], studying TMA patients with congenital ADAMTS13 deficiency and patients with ADAMTS13 inhibitors, reported that four out of six patients $(66 \%)$ had moderately decreased $\mathrm{C} 3$ levels in the acute phase of the disease, indicative of complement activation and consumption. In our study we observed decreased C3 levels in 2/13 TTP patients in the acute phase (Fig. 1). The lower frequency of C3 decrease in our cohort, as compared with the six patients with TMA in the study of Ruiz-Torres, may be related to patient selection, because we did not include patients with the congenital form of TTP.

As TTP due to the presence of anti-ADAMTS13 inhibitors can also be considered as an immune-complex disease, our findings may represent an epiphenomenon of this process. Indeed, the activation of the $\mathrm{C} 3 \mathrm{a}$ and terminal pathway was, rather weakly, linked to activation levels of the classical pathway. Furthermore, the sustained presence of ADAMTS13 inhibitor in complete remission was also linked to increased complement activation.

However, previous literature data and our current observations may also indicate that activation of complement plays a pathogenic role in TTP due to ADAMTS13 deficiency with inhibitors. According to the 'two-hit model', deficiency of ADAMTS13 predisposes to microvascular thrombosis but TTP supervenes only after a triggering event occurs. The nature of these triggering events is poorly understood currently, because the vast majority of TTP patients present without obvious clinical triggers. Potential triggering events include common infections and pregnancy, both known by their endothelial cell activating ability with increased secretion of ultra-large VWF and P-selectin expression. Interestingly, infections and pregnancy may also induce activation of the complement system. Soluble complement activation related mediators, including anaphylatoxins and the terminal complement complex SC5b-9, may directly activate endothelial cells $[11,12]$, neutrophils $[13,14]$ and platelets $[15,16]$. Indeed, plasma of TTP patients was shown to induce apoptosis of endothelial cells and platelets [17-20] and activation of neutrophils and monocytes [21], leading to the formation of platelet-leukocyte

Table 3 Correlation between complement activation product concentrations in the samples of patients with acute TTP, before the initiation of PEX-series $(n=13)$

\begin{tabular}{|c|c|c|c|c|c|}
\hline Variable & C1r-C1s-C1-INH & $\mathrm{C} 4 \mathrm{~d}$ & $\mathrm{Bb}$ & $\mathrm{C} 3 \mathrm{bBbP}$ & $\mathrm{C} 3 \mathrm{a}$ \\
\hline SC5b-9 & $0.183(0.548)^{*}$ & $0.727(0.017)$ & $-0.209(0.493)$ & $0.714(0.006)$ & $0.762(0.003)$ \\
\hline $\mathrm{C} 3 \mathrm{a}$ & $0.531(0.061)$ & $0.661(0.014)$ & $0.056(0.854)$ & $0.764(0.002)$ & - \\
\hline $\mathrm{C} 3 \mathrm{bBbP}$ & $0.255(0.401)$ & $0.657(0.015)$ & $-0.009(0.975)$ & - & - \\
\hline $\mathrm{Bb}$ & $0.396(0.181)$ & $0.308(0.307)$ & - & - & - \\
\hline $\mathrm{C} 4 \mathrm{~d}$ & $0.528(0.064)$ & - & - & - & - \\
\hline
\end{tabular}

*Pearson correlation coefficients and $P$-values were calculated after log-transformation of the variables. Statistically significant correlations are marked in bold. 
complexes [22]. Zwart et al. [23] showed that complement binding to apoptotic cells occurs in human plasma, and that the dominant mechanism involves classical pathway activation by IgM. In addition, complement activation by direct $\mathrm{Clq}$ binding to apoptotic blebs was also shown [24].

Several of our observations support the theory that complement activation in acute TTP patients may be, at least partly, initiated via the classical pathway by immune complexes and/or apoptotic cells. A strong correlation between C4d levels (indicative of classical and/or lectin pathway activation) and $\mathrm{C} 3 \mathrm{a}$ and SC5b-9 was observed (Table 3). In addition, a sustained presence of ADAMTS13 inhibitors after treatment of acute TTP was linked to high levels of C4d, $\mathrm{C} 3 \mathrm{bBbP}$ and $\mathrm{C} 3 \mathrm{a}$, indicating the presence of ongoing complement activation through classical and alternative pathways (Fig. 2). Moreover, in TTP patients in complete remission, the presence of ADAMTS13 inhibitor was tendentiously related to increased levels of C4d. It is known that ADAMTS13 inhibitors may belong to $\operatorname{IgG}(100 \%)$, IgA $(21 \%)$ or $\operatorname{IgM}$ $(7 \%)$ classes [25] with all $\operatorname{IgG}$ subclasses occurring. The most prevalent $(23 \%)$ anti-ADAMTS13 IgG subclass combination in the study of Ferrari et al. [25] was to have all (IgG1 to 4) subclasses. The human immunoglobulin classes and IgG subclasses differ in their ability to induce complement activation: while $\operatorname{IgG} 1$ and 3 mainly initiate the classical pathway through $\mathrm{Clq}$, at high epitope density and antibody excess IgG2 may initiate the alternative pathway like IgA [26]. Ferrari et al. [25,27] reported that $82-94 \%$ of the TTP patients in the acute first episode and $27-36 \%$ of patients with recurrent episodes had either of the complement activating IgG1, two or three, or IgA ADAMTS13 inhibitor; however, the presence of $\operatorname{IgA}$ inhibitors was mainly linked to that of IgG. Furthermore, it was recently also demonstrated by coimmunoprecipitation that circulating ADAMTS13 with immunoglobulins (ADAMTS13-specific IgG-IC) was present in a patient with refractory TTP, and the ADAMTS13-IgG-ICs followed an inverse kinetics to both the free $\operatorname{IgG}$ antiADAMTS13 autoantibody and ADAMTS13 activity [28]. It was concluded in the study by Ferrari et al. [28], that formation of ADAMTS13-specific immune complexes capturing all freely available ADAMTS13 should be considered in patients who are refractory to treatment. Although we did not look directly for ADAMTS13 immune complexes in our study, the observations on circulating ADAMTS13 immune complexes [28] and our above results on the presence of complement activation via the classical/lectin pathways, especially in patients with sustained presence of ADAMTS13 inhibitors, together indicate that circulating ADAMTS13 immune complexes may initiate complement activation in patients with TTP and contribute to the microangiopathic process.

We acknowledge potential limitations of our study. TTP is a rare disorder, and we were unable to enrol more patients in a reasonable short time-frame allowing the correct analysis of complement activation. Therefore, due to the low number of patients some of the analyses presented here are underpowered, and may be inconclusive, and therefore some of the conclusions have to be taken as preliminary, until independent confirmation is published. The study of patients with congenital ADAMTS13 deficiency would have helped to find out the role of ADAMTS13 inhibitor more exactly, but unfortunately, no such patients have been diagnosed in our centre until the end of our study. Moreover, because ADAMTS13 deficiency as a result of two heterozygous mutations (causing V88M and G1239V changes) together with a heterozygous mutation (causing an S890I change) in factor $\mathrm{H}$ of complement was found previously in a family [29], screening of complement genes previously associated with thrombotic microangiopathy would have been informative in our cohort, in relation to complement activation.

In conclusion, here we report the first clinical evidence of increased complement activation in acute TTP, and that therapeutic plasma exchange significantly decreased the levels of proinflammatory and cell-injuring complement activation products. Our data indicate that the classical/lectin and alternative pathways may initiate the terminal pathway in TTP. In addition, the sustained presence of ADAMTS13 inhibitors in $\mathrm{CR}$ is linked to higher complement activation product levels $\mathrm{C} 4 \mathrm{~d}, \mathrm{C} 3 \mathrm{bBbP}$ and $\mathrm{C} 3 \mathrm{a}$, indicative of the ongoing activation of the classical and alternative pathways. These data, if confirmed in other cohorts, may form the rationale for application of specific therapeutics aimed at controlling complement activation in TTP.

\section{Addendum}

Study concept and design: M. Réti, P. Farkas and Z. Prohászka. Experimental procedures: D. Csuka and Z. Prohászka. Acquisition of data: M. Réti, P. Farkas, K. Rázsó, Á. Schlammadinger, M.L. Udvardy, K. Madách, G. Domján, C. Bereczki, G.S. Reusz and A.J. Szabó. Analysis and interpretation of data: Z. Prohászka, D. Csuka, M. Réti and P. Farkas. Critical writing of the manuscript: M. Réti, P. Farkas and Z. Prohászka. Critical revision of the manuscript for important intellectual content: M. Réti, P. Farkas, D. Csuka, K. Rázsó, Á. Schlammadinger, M.L. Udvardy, K. Madách, G. Domján, C. Bereczki, G.S. Reusz and A.J. Szabó. Obtaining funding: Z. Prohászka. Study supervision: M. Réti and Z. Prohászka.

\section{Acknowledgements}

The authors are grateful for the expert medical support from J. Demeter, K. Gadó and G. Radványi, and the for the excellent technical support from I. Szigeti, M. Kókai as well as for the expert medical support from members of the following departments: National Institute of Hematology, Blood Transfusion and Immunology (Department of Hematology, Department of Hemapheresis); National Medical Center (Department of Hematology and Stem-cell transplantation, Department of Anaesthesiology and Intensive Care); St István and St László Hospital of Budapest (Department of Hematology and Stem 
cell transplantation, Department of Internal Medicine and Hematology, Department of Anaesthesiology and Intensive Care); National Blood Transfusion Service; Semmelweis University (Department of Anaesthesiology and Intensive Therapy, and Central Laboratory, Kútvölgyi Clinical Center); and staff of the Haemobil Health Care Ltd Service. We are grateful to our patients for their participation in the study. The study was financially supported by a grant from the National Research Fund of Hungary (T100687 to ZP). We would like to acknowledge the critical reading of the manuscript and suggestions of G. Remuzzi and M. Noris with many thanks.

\section{Disclosure of Conflict of Interests}

The authors state that they have no conflict of interest.

\section{References}

1 Sadler JE. von Willebrand factor, ADAMTS13, and thrombotic thrombocytopenic purpura. Blood 2008; 112: 11-8.

2 Moake J. Thrombotic microangiopathies: multimers, metalloprotease, and beyond. Clin Transl Sci 2009; 2: 366-73.

3 Tsai HM, Lian EC. Antibodies to von Willebrand factor-cleaving protease in acute thrombotic thrombocytopenic purpura. $N$ Engl $J$ Med 1998; 339: 1585-94.

4 Lotta LA, Garagiola I, Palla R, Cairo A, Peyvandi F. ADAMTS13 mutations and polymorphisms in congenital thrombotic thrombocytopenic purpura. Hum Mutat 2010; 31: 11-9.

5 Galbusera M, Noris M, Remuzzi G. Inherited thrombotic thrombocytopenic purpura. Haematologica 2009; 94: 166-70.

6 Wright JF, Wang H, Hornstein A, Hogarth M, Mody M, Garvey MB, Blanchette V, Rock G, Freedman J. Characterization of platelet glycoproteins and platelet/endothelial cell antibodies in patients with thrombotic thrombocytopenic purpura. Br J Haematol 1999; 107: 54655.

7 Ruiz-Torres MP, Casiraghi F, Galbusera M, Macconi D, Gastoldi S, Todeschini M, Porrati F, Belotti D, Pogliani EM, Noris M, Remuzzi G. Complement activation: the missing link between ADAMTS-13 deficiency and microvascular thrombosis of thrombotic microangiopathies. Thromb Haemost 2005; 93: 443-52.

8 Cat R, Rosario NA, de Messias IT, Resener TD, Kirschfink M. Evaluation of complement activation in premature newborn infants with hyaline membrane disease. Eur J Pediatr 1993; 152: 205-8.

9 Csuka D, Fust G, Farkas H, Varga L. Parameters of the classical complement pathway predict disease severity in hereditary angioedema. Clin Immunol 2011; 139: 85-93.

10 Gombos T, Makó V, Cervenak L, Papassotiriou J, Kunde J, Hársfalvi J, Förhécz Z, Pozsonyi Z, Borgulya G, Jánoskuti L, Prohászka Z. Levels of von Willebrand factor antigen and von Willebrand factor cleaving protease (ADAMTS13) activity predict clinical events in chronic heart failure. Thromb Haemost 2009; 102: 573-80.

11 Monsinjon T, Gasque P, Chan P, Ischenko A, Brady JJ, Fontaine MC. Regulation by complement C3a and C5a anaphylatoxins of cytokine production in human umbilical vein endothelial cells. Faseb $J$ 2003; 17: 1003-14.

12 Tedesco F, Pausa M, Nardon E, Introna M, Mantovani A, Dobrina A. The cytolytically inactive terminal complement complex activates endothelial cells to express adhesion molecules and tissue factor procoagulant activity. J Exp Med 1997; 185: 1619-27.

13 Camous L, Roumenina L, Bigot S, Brachemi S, Frémeaux-Bacchi V, Lesavre P, Halbwachs-Mecarelli L. Complement alternative pathway acts as a positive feedback amplification of neutrophil activation. Blood 2011; 117: 1340-9.
14 Castellheim A, Pharo A, Fung M, Saugstad OD, Mollnes TE. Complement C5a is a key mediator of meconium-induced neutrophil activation. Pediatr Res 2005; 57: 242-7.

15 Sims PJ, Wiedmer T. The response of human platelets to activated components of the complement system. Immunol Today 1991; 12: 33842.

16 Wiedmer T, Ando B, Sims PJ. Complement C5b-9-stimulated platelet secretion is associated with a $\mathrm{Ca}^{2+}$-initiated activation of cellular protein kinases. $J$ Biol Chem 1987; 262: 13674-81.

17 Burns ER, Zucker-Franklin D. Pathologic effects of plasma from patients with thrombotic thrombocytopenic purpura on platelets and cultured vascular endothelial cells. Blood 1982; 60: 1030-7.

$18 \mathrm{Wu}$ XW, Li QZ, Lian EC. Plasma from a patient with thrombotic thrombocytopenic purpura induces endothelial cell apoptosis and platelet aggregation. Thromb Res 1999; 93: 79-87.

19 Dang CT, Magid MS, Weksler B, Chadburn A, Laurence J. Enhanced endothelial cell apoptosis in splenic tissues of patients with thrombotic thrombocytopenic purpura. Blood 1999; 93: 1264-70.

20 Mitra D, Jaffe EA, Weksler B, Hajjar KA, Soderland C, Laurence J. Thrombotic thrombocytopenic purpura and sporadic hemolytic-uremic syndrome plasmas induce apoptosis in restricted lineages of human microvascular endothelial cells. Blood 1997; 89: 1224-34.

21 Alvarez-Larran A, Petriz J, Martinez A, Sanz C, Pereira A. Plasma from patients with thrombotic thrombocytopenic purpura induces activation of human monocytes and polymorphonuclear neutrophils. Br J Haematol 2003; 120: 129-34.

22 Valant PA, Jy W, Horstman LL, Mao WW, Ahn YS. Thrombotic thrombocytopenic purpura plasma enhances platelet-leucocyte interaction in vitro. Br J Haematol 1998; 100: 24-32.

23 Zwart B, Ciurana C, Rensink I, Manoe R, Hack CE, Aarden LA. Complement activation by apoptotic cells occurs predominantly via IgM and is limited to late apoptotic (secondary necrotic) cells. Autoimmunity 2004; 37: 95-102.

24 Nauta AJ, Trouw LA, Daha MR, Tijsma O, Nieuwland R, Schwaeble WJ, Gingras AR, Mantovani A, Hack EC, Roos A. Direct binding of Clq to apoptotic cells and cell blebs induces complement activation. Eur J Immunol 2002; 32: 1726-36.

25 Ferrari S, Mudde GC, Rieger M, Veyradier A, Kremer Hovinga JA, Scheiflinger F. IgG subclass distribution of anti-ADAMTS13 antibodies in patients with acquired thrombotic thrombocytopenic purpura. J Thromb Haemost 2009; 7: 1703-10.

26 Lucisano Valim YM, Lachmann PJ. The effect of antibody isotype and antigenic epitope density on the complement-fixing activity of immune complexes: a systematic study using chimaeric anti-NIP antibodies with human Fc regions. Clin Exp Immunol 1991; 84: 1-8.

27 Ferrari S, Scheiflinger F, Rieger M, Mudde G, Wolf M, Coppo P, Girma JP, Azoulay E, Brun-Buisson C, Fakhouri F, Mira JP, Oksenhendler E, Poullin P, Rondeau E, Schleinitz N, Schlemmer B, Teboul JL, Vanhille P, Vernant JP, Meyer D, et al. Prognostic value of anti-ADAMTS 13 antibody features (Ig isotype, titer, and inhibitory effect) in a cohort of 35 adult French patients undergoing a first episode of thrombotic microangiopathy with undetectable ADAMTS 13 activity. Blood 2007; 109: 2815-22.

28 Ferrari S, Knöbl P, Kolovratova V, Plaimauer B, Turecek PL, Varadi K, Rottensteiner H, Scheiflinger F. Inverse correlation of free and immune complex-sequestered anti-ADAMTS13 antibodies in a patient with acquired thrombotic thrombocytopenic purpura. J Thromb Haemost 2011; 10: 156-8.

29 Noris M, Bucchioni S, Galbusera M, Donadelli R, Bresin E, Castelletti F, Caprioli J, Brioschi S, Scheiflinger F, Remuzzi G, International Registry of Recurrent and Familial HUS/TTP. Complement factor H mutation in familial thrombotic thrombocytopenic purpura with ADAMTS13 deficiency and renal involvement. J Am Soc Nephrol 2005; 16: 1177-83. 